\title{
Operational Planning of Distribution Networks Based on Utility Planning Concepts
}

DOI:

10.1109/TPWRS.2018.2885275

Document Version

Accepted author manuscript

Link to publication record in Manchester Research Explorer

\section{Citation for published version (APA):}

Levi, V., \& Mansor, N. N. (2018). Operational Planning of Distribution Networks Based on Utility Planning

Concepts. IEEE Transactions on Power Systems, 1-1. https://doi.org/10.1109/TPWRS.2018.2885275

\section{Published in:}

IEEE Transactions on Power Systems

\section{Citing this paper}

Please note that where the full-text provided on Manchester Research Explorer is the Author Accepted Manuscript or Proof version this may differ from the final Published version. If citing, it is advised that you check and use the publisher's definitive version.

\section{General rights}

Copyright and moral rights for the publications made accessible in the Research Explorer are retained by the authors and/or other copyright owners and it is a condition of accessing publications that users recognise and abide by the legal requirements associated with these rights.

\section{Takedown policy}

If you believe that this document breaches copyright please refer to the University of Manchester's Takedown Procedures [http://man.ac.uk/04Y6Bo] or contact uml.scholarlycommunications@manchester.ac.uk providing relevant details, so we can investigate your claim.

\section{OPEN ACCESS}




\title{
Operational Planning of Distribution Networks Based on Utility Planning Concepts
}

\author{
Nurulafiqah Mansor, Student Member, IEEE, Victor Levi, Senior Member, IEEE
}

\begin{abstract}
The paper presents the operational planning of medium voltage $(11 \mathrm{kV} ; 6.6 \mathrm{kV})$ distribution networks that is an integral part of the previously developed integrated planning approach based on utility planning concepts. The operational planning problem is decoupled from the investment planning stage and it is further divided into two phases, the quality of supply $(Q 0 S)$ planning and the minimization of operational costs. The QoS planning maximizes the benefits of the regulatory incentive regime by installing and automating switchgear, as well as finding optimal normally open points (NOPs). It is solved in two ways, by applying genetic algorithm (GA) optimization and then the approach based on engineering rules. Operational cost minimization considers costs of $O \& M$, switching, losses and reliability. It includes security constraints for radially operated networks and allows that the locations of new switchgear from the QoS stage are changed. The simplified version of the model is also intended to be used as a real-time network reconfiguration tool. The entire methodology is tested on the 69-bus test system.
\end{abstract}

Index Terms - Distribution operations planning, Quality of supply, Operations cost minimization, Mixed-integer nonlinear optimization, Optimal reconfiguration.

\section{NOMENCLATURE}

Sets

$\Omega_{l} \quad$ Set of all branches

$\Omega_{b} \quad$ Set of all buses

$\Omega_{S} \quad$ Set of primary substations

$\Omega_{F s} \quad$ Set of feeders connected to substation $s$

$\Omega_{S W e x}$ Set of existing switchgear

$\Omega_{C B / \text { RECnew }}$ Set of new CBs/reclosers

$\Omega_{\text {SWnew }} \quad$ Set of new switches

$\Omega_{N O P} \quad$ Set of all normally open switches to adjacent feeders

$\Omega_{k} \quad$ Set of intact/non - intact regimes $\left(\Omega_{k}=\Omega_{k}^{\text {nor }} \cup \Omega_{k}^{a b n}\right)$

$\Omega_{k}^{\text {nor }} \quad$ Set of intact regimes

$\Omega_{k}^{a b n} \quad$ Set of non - intact (contingent) regimes

Variables

$n x_{i j}, n y_{i j}$ Binary construction variables associated with new switches and CBs/reclosers in branch $i j$

$n x a_{i j}, n y a_{i j}$ Binary variables for automation of switches \& CBs

$m_{s}^{k} \quad$ Binary variable denoting whether primary substation $s$

supplies power to the network in regime $k$ or not

$m_{f s}^{k} \quad$ Binary variable denoting use of backfeeding feeder $f$ at primary substation $s$ in regime $k$

$P_{G i}^{k} \quad$ Active power from primary sub at node $i$ in regime $k$

N. Mansor and V. Levi are with the School of Electrical and Electronic Engineering, Faculty of Science and Engineering, University of Manchester, UK (email: nurulafiqahnadzirah.mansor@postgrad.manchester.ac.uk; victor.levi@manchester.ac.uk).
$Q_{G i}^{k} \quad$ Reactive power from primary sub at node $i$ in regime $k$

$o c_{i j}^{k} \quad$ Binary operation variable for branch $i j$ in regime $k$; equal 1 for closed branches and 0 for open branches

$f_{i j}^{k} \quad$ Fictitious power flow in branch $i j$, regime $k$ due to DG

$P L C_{i}^{k} \quad$ Active power load curtailment at node $i$ in regime $k$

\section{Functions}

$R E V_{Q o S} \quad$ Utility net revenue under QoS incentive regime

$\triangle C I_{\tau} \quad$ SAIFI improvement due to QoS actions in year $\tau$ $\triangle C M L_{\tau} \quad$ SAIDI improvement due to QoS actions in year $\tau$ $C O \& M_{\text {sub }}(t)$ Substation O\&M cost in $€$ in reconfiguration period $t$

$C M_{\text {line }}(t)$ Line maintenance cost in $€$ in reconfig. period $t$

$C_{\text {loss }}(t) \quad$ Cost of line losses in $€$ in reconfiguration period $t$

$\operatorname{CSW}(t) \quad$ Cost of switching in $€$ in reconfiguration period $t$

$C_{\text {inter }}(t)$ Interruption cost in $€$ in reconfiguration period $t$

$P_{i j}^{k}(\cdot), Q_{i j}^{k}(\cdot)$ Active \& reactive power flows in branch $i j$ in regime $k$

$I_{i j}^{k}(\cdot) \quad$ Current magnitude in branch $i j$ in regime $k$

\section{Parameters}

$k_{t}^{N P V} \quad$ NPV factor for discounting in time period $t$

$C I_{\text {inc }} \quad$ CI incentive in $E /$ customer

$C M L_{\text {inc }} \quad$ CML incentive in $€ /$ (customer $\cdot$ hour)

$T \quad$ Length of the control (yr) or reconfiguration period (h)

$C R F \quad$ Capital recovery factor

$c_{i j}^{S W}, c_{i j}^{S W A}$ Cost of a new switch and its automation in $€$

$c_{i j}^{C B}, c_{i j}^{C B A} \quad$ Cost of a new $\mathrm{CB} /$ recloser and its automation in $£$

$t r, t s \quad$ Repair and switching time in $\mathrm{h}$

$\lambda_{p}, N_{n} \quad$ Failure rate of section \& number of customers at node

$S_{S}^{\max } \quad$ Rating of primary substation $s$ in MVA

$\operatorname{len}_{i j} \quad$ Length of branch $i j$

$\mathrm{Pr}_{k} \quad$ Probability of operation regime $k$

$\mathrm{CO}_{\text {sub }} \quad$ Substation annual operation cost in $€ /(\mathrm{MVAh} \cdot \mathrm{yr})$

$C M_{\text {sub }} \quad$ Substation annual maintenance cost in $£ /(\mathrm{MVA} \cdot \mathrm{yr})$

$C M S_{\text {line }} \quad$ Line specific annual maintenance cost in $€ /(\mathrm{km} \cdot \mathrm{yr})$

$C M_{C B-R E C} \quad \mathrm{CB}$ - recloser annual maintenance cost in $€ / \mathrm{yr}$

$C M_{F U S E}, C M_{S W I T}$ Fuse \& switch annual maintenance cost in $€ / \mathrm{yr}$

$C R_{i j} \quad$ Repair cost of line $i j$ in $€$

$\psi_{x x x i j}=0$ no switchgear in $i j ;=1$ with switchgear in $i j$

$C S_{\text {loss }} \quad$ Cost of losses in $€ / \mathrm{kWh}$ $=n x_{i j}$ with new switch; $=n y_{i j}$ with new $\mathrm{CB} / \mathrm{recl}$.

$\operatorname{Llf}(T) \quad$ Line loss factor in reconfiguration period $T$

$C_{S W} \quad$ Cost of a switching - existing switchgear in $£ /$ No. Op

$C_{C B-R E C L} \quad$ Cost of a switching - new CB/recloser in $£ /$ No. Op.

$C_{S W I T} \quad$ Cost of a switching - new switch in $£ /$ No. Op.

$o c_{i j}^{0} \quad$ Final status of switchgear in branch $i j$ in QoS stage

VOLL $L_{i} \quad$ Value of lost load at node $i$

$L f_{i}(T) \quad$ Load factor at node $i$ in reconfiguration period $T$

$P_{D G i}^{k}, Q_{D G i}^{k} \quad$ Active and reactive generation at node $i$, regime $k$

$P_{D i}^{k}, Q_{D i}^{k} \quad$ Active $\&$ reactive demand at node $i$ in regime $k$

$x_{i j}^{k}$

Fault parameter for branch $i j$ : 0 for outage; 1 otherwise Resistance of branch $i j$ 
$\left(\bar{I}_{i j}^{k}\right)$ Rating of circuit in branch $i j$, regime $k$

$\left(\bar{I}_{i j}\right)^{C B / R e c},\left(\bar{I}_{i j}\right)^{S W}$ Rating of new CB - recl. \& switch in branch $i j$

$\underline{V}^{k}, \bar{V}^{k} \quad$ Minimum \& maximum voltage limits in regime $k$

$\bar{N}_{D G} \quad$ Number of DG units - DG nodes

$N_{N O P} \quad$ Maximum number of NOPs used during outages

$N_{S} \quad$ Maximum number of substations during outages

$N_{F} \quad$ Maximum number of backfeeding feeders during outage

$K_{i} \quad$ Fictitious load equal 1 at DG node $i ; 0$ otherwise

$n_{b}^{k} \quad$ Total number of nodes in regime $k$

\section{INTRODUCTION}

$\mathrm{D}$ istribution network planning has been addressed from many angles using diverse mathematical models and solution methods [1-4]. This complex problem was often formulated as a multi-objective, multi-period optimization model [5-16], in which the multi-criterion objective is minimization of one or more cost terms related to capital investments, energy losses, reliability and O\&M [1,2]. Multiperiod planning is done using either static models $[6,7,14]$, or dynamic models $[5,8,15,16]$. It should be noted: a) Even if the static approach is applied, very diverse planning aspects are considered within a single model, which cannot be applied in real-life; and b) A single optimal trajectory produced by a dynamic model is even more rigid and inappropriate for use in power industry [17]. A few attempts were made to overcome the distribution planning complexity by either decomposing the multi-objective optimizations $[18,19]$, or by separate optimization of certain planning aspects [20-22]. This group of methods is better suited to real-life applications but still lacks many concepts and features applied within the power industry.

This was the motivation for the development of the integrated planning methodology that supports the real-life structure of the distribution planning business [17], whose simplified flowchart is shown in Fig. 1. The integrated methodology makes use of static models and it is based on the two-stage optimization. The first stage solves investment optimization, whilst the second stage considers additional operational planning aspects. The two planning stages are connected using the probabilistic decision tree(s) - Section II.

This paper presents the operational stage of the integrated distribution planning (stage II in Fig. 1) that is aligned with the real-life planning in the UK. Following the replacement and reinforcement investment planning (stage I in Fig. 1), QoS and operations planning are done independently. QoS studies are performed on an irregular basis, usually initiated by poor performance and/or changes in the regulatory QoS incentive regime. The essential objective is to improve SAIFI (CI) and SAIDI $(C M L)$ reliability indices by automating and installing switchgear, reconfiguring networks, etc. On the other hand, optimal network reconfiguration is studied regularly once or twice per year for non-automated networks, or even on an hourly basis for fully-automated networks; the objective is to find the NOPs so that the total operational costs are minimized. However, the review of the existing approaches has shown that in the best case they only satisfy some of the aspects required for the real-life planning of distribution networks; these requirements are discussed above and shown in Fig. 1. Methods [12,14,15,23-28] combine reinforcement planning with reliability aspects; reliability costs based on non-supplied energy are included in the objective in $[12,14,15,23]$, constraints on specific reliability indices are modelled within investment optimization models [24-27], whilst [28] calculates reliability indices following the expansion planning. The common drawbacks are: a) Reinforcement planning is not based on national planning standards (e.g. [29] in the UK); and b) Reliability is not linked s to the regulatory QoS regime expressed through incentives on $C I s$ and CMLs but on the customer outage costs. In the second group of approaches, multi-objective optimization models consider network reconfiguration [20], optimal switch placement [21,30,31] and greenfield network planning [32] giving Pareto set of optimal solutions. The main disadvantages are twofold: a) A decision maker needs to specify preferences through an additional procedure to obtain a single "optimal" solution; and b) Selection of individual objectives is not in line with the distribution business requirements. Finally, methods [22,33-48] consider optimal placement of switching devices using a single, weighted objective function. Approaches [22,33-46] combine switch investments and customer outage costs, whilst minimization of investments subject to maximized restored load is done in [47,48]; the disadvantages are similar as before. It is worth noting that the sophisticated optimization model in [49] offers a CI-CML improvement method that is close to reality; however it is limited to solving the network reconfiguration on a specific, non-general network due to model complexity.

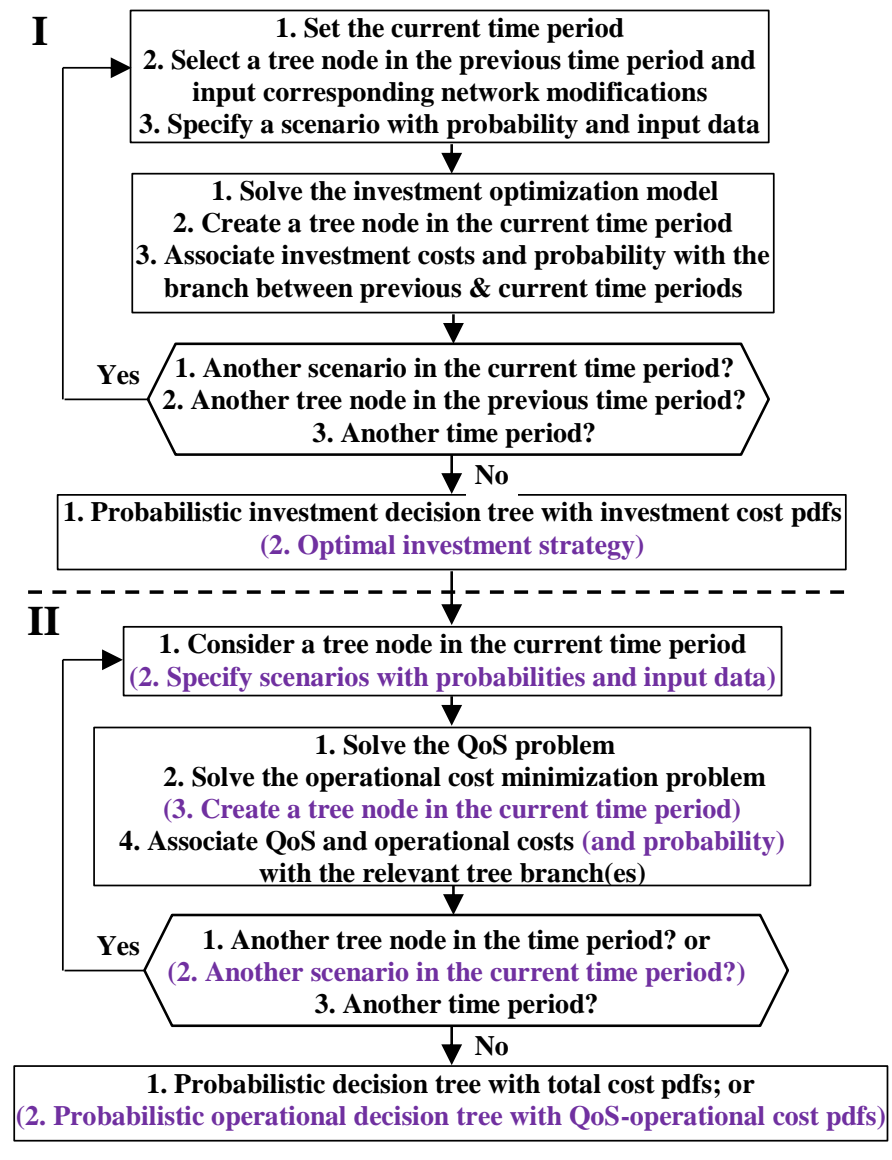

Figure 1.-Simplified global algorithm of the integrated planning methodology

The proposed operational planning procedure is divided into two sub-stages to mimic the real-life distribution business: a) 
QoS planning; and b) Minimization of operational costs. QoS planning addresses construction and automation of switchgear to meet SAIFI (CI) and SAIDI (CML) benchmarks and to maximize QoS benefits [50]. The problem is solved in two ways, using the two-stage GA optimization and approach based on UK engineering rules. The first GA stage optimizes locations and automation of switchgear, whilst the second GA stage considers network reconfiguration. Network reconfiguration in each loop is done using the branch exchange method and the developed reliability rules analogous to the loss approach [51]. The engineering rule based approach maximizes $C I$ and $C M L$ benefits by using the developed algorithm with company specific rules for switchgear installation and automation. Optimal network configuration is found using a greedy search algorithm [52].

The second operational planning stage is minimization of operational costs that consist of O\&M, switching, losses and interruption costs. It is formulated as a mixed-integer nonlinear optimization problem and it produces optimal network configurations, whereby locations of new switchgear can be varied in the vicinity of 'optimal' QoS solutions.

The essential contribution of the paper is development of a methodology for operational planning of distribution networks that can be applied in real-life because it mimics the distribution business in utilities. The individual contributions are as follows:

- The operational planning is integrated into the comprehensive methodology adequate for distribution planning in utilities [17] as an independent entity, because corresponding planning stages are done by separate departments on different timescales.

- Various uncertainties are modelled by considering future scenarios that are built into the probabilistic decision tree [17]. The original concept, developed in [17], is modified by specifying two probabilistic decision trees and applying "tree trimming" to reduce the computation burden - Section II.

- Operation problem is decomposed into two sub-stages, namely, QoS planning and operational cost minimization. This is an important feature in order to apply the model in the day-to-day business in utilities, as discussed above.

- QoS stage is solved by applying the GA optimization and engineering-rule based approach. It is proposed to prioritize network loops when studying network reconfiguration and to base branch exchange approach on reliability rules within the GA optimization.

- The rule based QoS methodology makes use of engineering concepts often used in utilities; it can be applied without any additional specialized software.

\section{II.PROBABILISTIC DECISION TREES}

Various parameters of distribution planning are uncertain, e.g. wind and solar power generations, load growth, asset availability, future capital costs, etc. The models and solution methodologies developed to address uncertainties can be classified into the following broad categories: a) Monte Carlo simulation nested within a single- or multi-objective optimization model [53-58]; b) Probabilistic-stochastic models incorporated into optimization routines [59-67]; c) Stochastic programming models [68-69]; and d) "Scenario-like" models integrated within optimization models [70-74]. The most important drawbacks are: a) Distribution planning in utilities is always based on deterministic criteria and there is no simple way to link them with the probabilistic results; b) Results interpretation can be very difficult as well as subsequent decision making using these results; and c) Large amount of data may be required. The first two downsides are the biggest obstacle in applying any such method in real-life, because design engineers would never propose a solution they don't understand and/or is not compliant with the planning standards. In that context, the last group of methods [70-74] is best suited for real-life planning; however, all methods produce amalgamated solutions for all considered scenarios in the horizon year. This can be deemed as an advantage in the academic world because the global optimum is obtained; however, in real-life, each investment decision needs to be clearly justified to the Regulator and amalgamated solutions are not welcome.

This was the motivation to develop the probabilistic decision tree concept in [17] in order to get easily understandable planning solutions compliant with national planning standards. A table of scenarios and associated probabilities related to new DG connections and load growth is created for all years first. The investment optimization [17] is then solved for all scenarios, a probabilistic decision tree is created, and the operational problem is studied for each tree node (Fig. 2). Here, discounted investment \& operational costs are denoted as $(C+O)_{x-y}$ and scenario probabilities as $P r_{x-y}$. The end results are the discrete total cost pdfs by planning intervals.

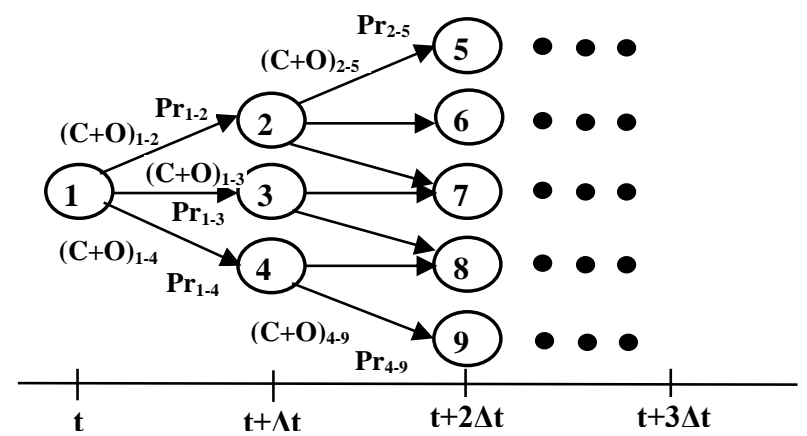

Figure 2. - Illustrative example of a probabilistic decision tree [17]

Practical application of the above concept has shown two drawbacks: a) Investment and operation problems are a part of the single, integrated methodology which cannot be applied in utilities; and b) Operation problem needs to be solved for each decision tree node requiring extensive studies. These were the reasons to modify the original concept in the following way:

- After having solved the investment problem and created the probabilistic (investment) decision tree, the best development strategy is found across all years in the planning period. The yearly solutions can be based on the plans with the highest probability, or several aggregated plans whose probability is greater than the pre-specified threshold. This results in a single "best" plan in each year.

- Operational problem is solved for the yearly development plans on the optimal strategy. A new probabilistic (operational) decision tree is built using a reduced set of 
scenarios and a shorter planning period (less uncertainty). Discounted operational costs and scenario probabilities are associated with tree branches. Best yearly plans are found as before.

These methodological steps are shown in Fig. 1 in brackets.

\section{QUALITY-OF-SUPPLy PLANNING}

QoS investment planning of MV networks usually considers installation of switchgear, fault passage indicators and short cable sections, as well as switchgear automation and network reconfiguration. QoS investments are materialized when additional funds are approved by the Regulator; this can be either in the form of the QoS incentive scheme that rewards and penalizes reliability performance, or an additional QoS investment fund is provided to meet the reliability targets. This paper presents QoS planning based on the UK incentive regime.

Two QoS methodologies are developed in this paper: a) Engineering (rule) based approach; and b) Optimization (GA) approach. The latter produces the optimal solution and it is used to validate the engineering approach which is currently being applied in the UK utilities.

\section{A. Genetic Optimization}

QoS stage considers construction/automation of switchgear and optimal network reconfiguration; it is executed once for each yearly scenario. The following objective is maximized:

$$
\begin{aligned}
R E V_{Q O S}=k_{t}^{N P V} \cdot & \left\{\sum_{\tau}\left(\Delta C I_{\tau} * C I_{i n c}+\Delta C M L_{\tau} * C M L_{i n c}\right)\right. \\
& -T \cdot C R F \cdot\left[\sum_{i j \in \Omega_{l}}\left(c_{i j}^{S W} \cdot n x_{i j}+c_{i j}^{C B} \cdot n y_{i j}\right)\right. \\
& \left.\left.-\sum_{i j \in \Omega_{l}}\left(c_{i j}^{S W A} \cdot n x a_{i j}+c_{i j}^{C B A} \cdot n y a_{i j}\right)\right]\right\}
\end{aligned}
$$

The first sum in (1) is over years $\tau$ of the control period(s), whose length is $T$, and gives the $C I$ and $C M L$ benefits with respect to the network base case. The second sum is annuitized investment costs in new switches and circuit breakers in all branches $i j$, whilst the third term is annuitized cost of switchgear automation. The logical constraints are explicitly handled within the GA and not added to (1) via penalty terms.

The first step of the QoS stage (Fig. 3) is calculation of base indices $C I^{b}$ and $C M L^{b}$ [75] for the considered network. The GA procedure for optimal investments and network configuration is initiated next. The first stage is outer iteration loop over QoS investments defined via a randomly generated 'investment chromosome', which is followed by update of the cost terms in objective (1). The inner iteration loop considers network loops in different order; the initial network loop sequence is established by reliability-based loop prioritization, which is followed by the random modification of the network loop sequence giving the 'network loop chromosome'. Network reconfiguration is done by studying network loops in turn and applying the branch exchange method [76,77] based on the proposed reliability rules. Here, the optimal branch exchange gives the (radial) network configurations by loops with the minimal $£$ value of $C I s$ and $C M L s$, requiring recalculation of the $C I / C M L$ terms with respect to base values in objective (1). Final results are optimal QoS investments as well as corresponding network configurations.

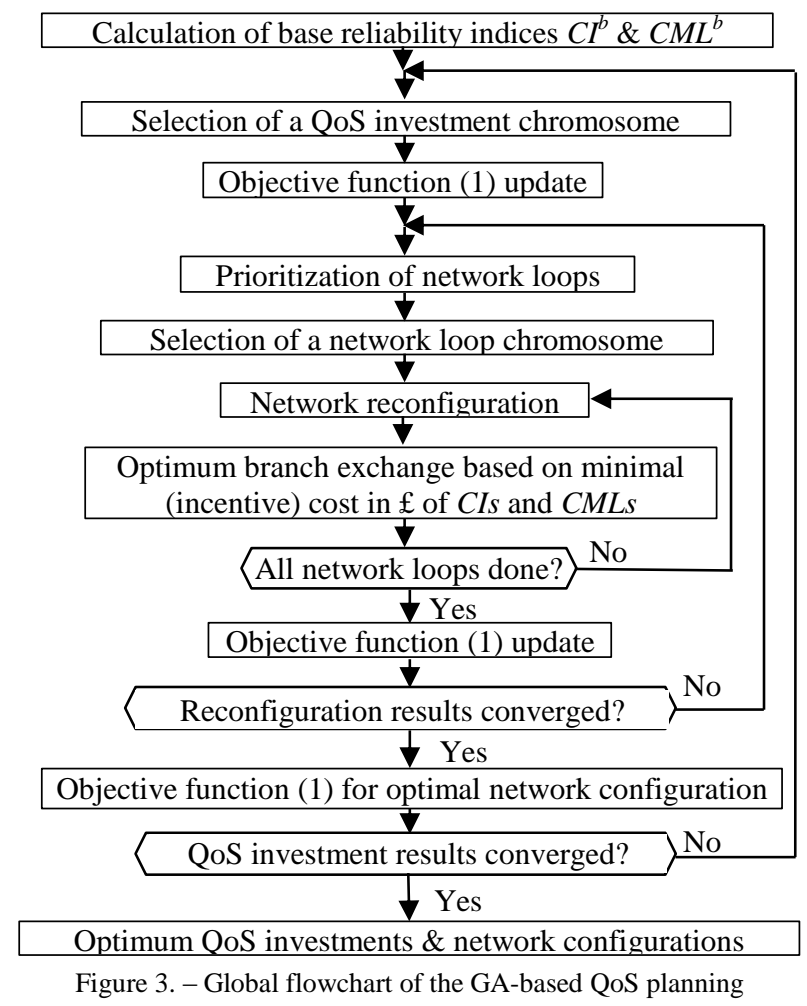

a) Genetic Algorithm

GA chromosomes consist of 'QoS investment' and 'network loop' chromosomes (Fig. 4). The former has an entry for each section and it is necessary to distinguish between sections with (for automation) and without switchgear (for construction and automation). Each section option is encoded into a binary string, the single point crossover and mutation operators are implemented, whereby associated probabilities and step lengths are adaptively changed in order to do only local search around "good" genetic instances with high objective (1) and global search of "bad" instances [51,78]. Network loop chromosomes define the sequence of network loops to be studied for reconfiguration. The starting point is loop prioritization, which is based on the $£$ value of individual feeder $C I s$ and $C M L s$. The loop sequence is then modified by reversing the loop order between two randomly generated numbers (crossover) and by applying swap mutation [79].

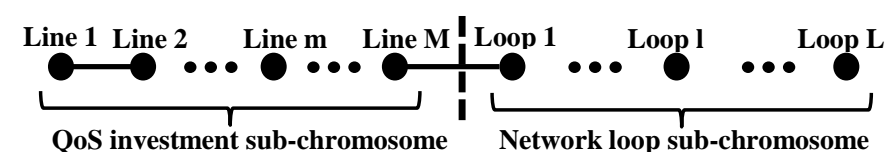
Figure 4. - QoS investment and network loop chromosomes

\section{b) Branch Exchange Method}

In a radial distribution network, closing a normally open switch and opening another one in the loop is called branch exchange [76]. In QoS planning, the objective is to find the optimal branch exchange that minimizes the cost of loop CIs and $C M L s$ based on incentive rates $C I_{\text {inc }}$ and $C M L_{\text {inc }}$; this is equivalent to maximizing the reliability benefit in (1). To avoid the exhaustive search, the following rules are developed: 
a) There are two switches in each section: open the section with the largest failure rate.

b) There is one automated switch in each section: calculate product $\lambda_{p} \cdot t r \cdot N_{p}$ for the currently open section $p$ as well as $\lambda_{n} \cdot \operatorname{tr} \cdot N_{n}$ for sections $n$ on Feeder 1 (Fig. 5) and $\lambda_{m} \cdot \operatorname{tr} \cdot N_{m}$ for sections $m$ on Feeder 2. The section $n$ or $m$ with most negative $\left(\lambda_{p} \cdot \operatorname{tr} \cdot N_{p}-\lambda_{n} \cdot \operatorname{tr} \cdot N_{n}\right)$ or $\left(\lambda_{p} \cdot \operatorname{tr} \cdot N_{p}-\lambda_{m} \cdot \operatorname{tr} \cdot N_{m}\right)$ is open.

c) There is one switch at the beginning of each section $n$ and $m: \triangle C M L_{\text {repair }}$ is calculated as under b) whilst $\triangle C M L_{\text {switch }}$ is slightly different when sections $n$ on Feeder 1 and sections $m$ on Feeder 2 are opened. For example, if section $n$ is opened, $\triangle C M L_{\text {switch }}=t s \cdot\left\{\left[\lambda_{p}+\Sigma_{j}\left(\lambda_{j}^{T R}\right)\right] \Sigma_{m} N_{m}-\right.$ $\left[\lambda_{n}+\Sigma_{j}\left(\lambda_{j}^{T R}\right)\right] \cdot \Sigma_{j}\left(N_{j}\right)^{R E T}+\left[\lambda_{p}+\Sigma_{m} \lambda_{m}-\Sigma_{j}\left(\lambda_{j}^{R E T}\right)\right] \Sigma_{j}\left(N_{j}\right)^{T R}-$ $\left.\lambda_{p} \cdot N_{n+1}-\lambda_{n} \cdot N_{n+1}\right\}$, where superscripts ${ }^{T R}$ and ${ }^{R E T}$ denote transferred and retrained sections and customers. The section with the most negative $\left(\triangle C M L_{\text {repair }}+\triangle C M L_{\text {switch }}\right)$ is opened.

d) There is a switch in a few sections $n$ and $m$ on both feeders. When the number of switches is small, it is often simpler to recalculate $C I s$ and $C M L s$ for all normally open points.

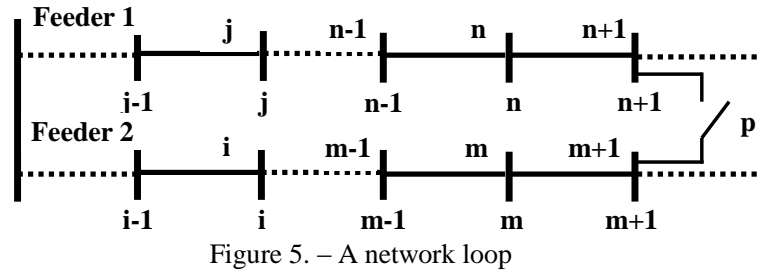

\section{B. Rule Based Approach}

In most of distribution companies, QoS planning is done using engineering rules and commercial software [80]. The first step is data pre-processing (Fig. 6) and circuits on the list are then studied in turn; the next step is to automate and install switchgear. The following rules are used: (a) If the regulatory regime defines QoS incentives, the cost of QoS programme

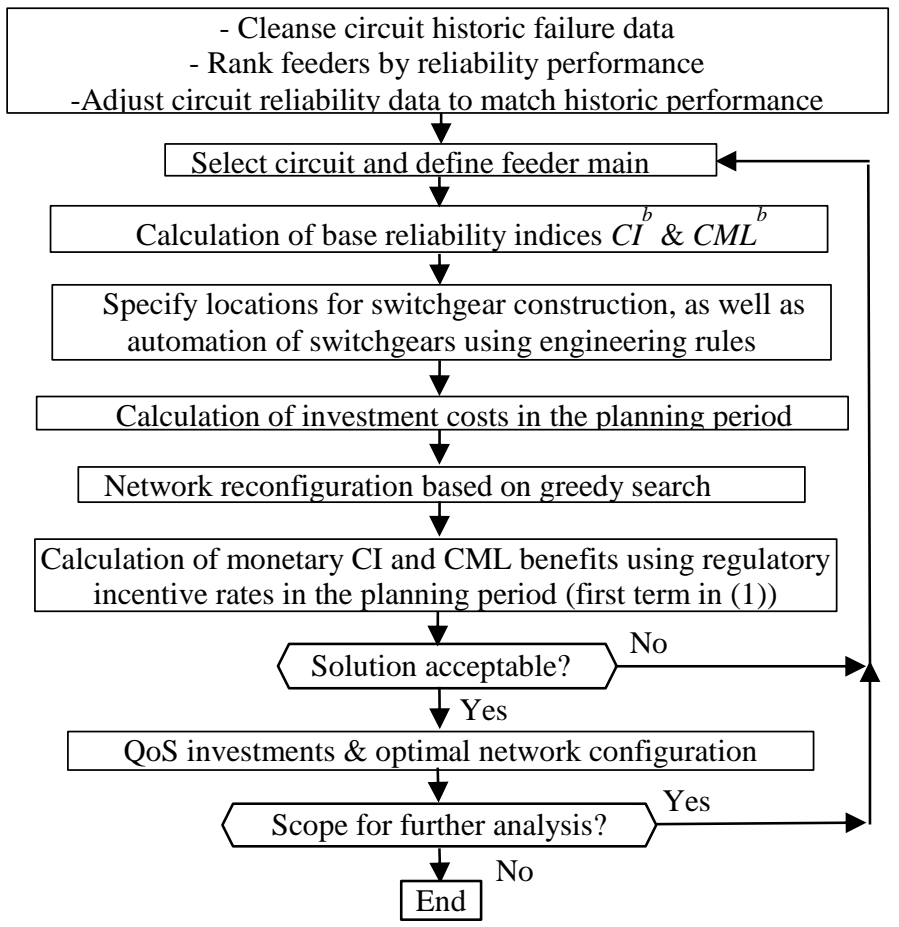

Figure 6. - Global flowchart for the rule based approach should match the $£$ reliability benefits; otherwise the QoS budget needs to be specified; (b) New switchgear is usually installed on the worst performing circuits, which are typically long rural and mixed circuits; (c) Construction of fault breaking devices is done at the beginning of laterals or around mid-points of the feeder main and 'important' laterals; new circuit breakers and NOPs should be automated; (d) Switches are placed in locations so that the switching zones are balanced, that is, the product of the zonal circuit length and customer number is approximately uniform across zones; and (e) Automation of switches is done in pairs, starting with the NOP and mid-point switches.

Network reconfiguration is done in the next stage, whereby a single circuit can be studied several times to find the highest objective (1). A greedy search algorithm [52] was used for this purpose; an example is shown in section V.

\section{MinimiZATION OF OPERATIONAL COSTS}

\section{A. General Model}

In real-life, frequency of reconfiguration is dependent on the medium voltage network automation level. It is usually done once (or twice) a year in case of non-automated networks, whilst it can be done every hour where the full automation exists. 'Time loop' is therefore set outside the optimization model, which is repeatedly solved over time intervals.

A composite objective function is used to minimize operational costs. The optimal locations of new switchgear therefore can be changed in the vicinity of the 'optimal' QoS solutions. The composite objective function has five terms:

$$
\begin{aligned}
& C O \& M_{\text {sub }}(t)=k_{t}^{N P V} \cdot\left(C O_{s u b}+C M_{\text {sub }} / 8760\right) \cdot T \cdot \\
& \sum_{k \in \Omega_{k}} \operatorname{Pr}_{k} \cdot \sum_{s} m_{S}^{k} \cdot S_{s}^{\text {max }} \\
& C M_{\text {line }}(t)=k_{t}^{N P V} \cdot T \cdot \sum_{k \in \Omega_{k}} P r_{k} \cdot \sum_{i j \in \Omega_{l}} o c_{i j}^{k} \cdot x_{i j}^{k} \cdot \\
& {\left[C M S_{\text {line }} \cdot \frac{l e n_{i j}}{8760}+\left(1-x_{i j}^{k}\right) \cdot C R_{i j}+C M_{C B-R E C} \cdot\right.} \\
& \frac{\psi_{C B-R E C i j}}{8760}+C M_{F U S E} \cdot \frac{\psi_{F U S E i j}}{8760}+C M_{S W I T} \cdot \frac{\psi_{S W I T i j}}{8760} ; \quad \psi_{x x x i j}= \\
& 0 \text { or } 1 \text { or } n x_{i j} \text { or } n y_{i j} \\
& C_{l o s s}(t)=k_{t}^{N P V} \cdot C S_{l o s s} \cdot T \cdot \sum_{k \in \Omega_{k}} \operatorname{Pr}_{k} \cdot\left[\sum_{i j \in \Omega_{l}} o c_{i j}^{k} \cdot x_{i j}^{k} \cdot\right. \\
& \left.L l f(T) \cdot r_{i j} \cdot I_{i j}^{k}(\cdot)^{2}\right] \\
& C S W(t)=k_{t}^{N P V} \cdot \sum_{k \in \Omega_{k}} \operatorname{Pr}_{k} \cdot\left\{C _ { S W } \cdot \sum _ { i j \in \Omega _ { S W e x } } \left[o c_{i j}^{k}-\right.\right. \\
& \left.o c_{i j}^{0}\right]^{2} \cdot x_{i j}^{k}+C_{C B-R E C L} \cdot \sum_{i j \in \Omega_{C B-R E C n e w}} n y_{i j} \cdot\left[o c_{i j}^{k}-\right. \\
& \left.\left.o c_{i j}^{0}\right]^{2} \cdot x_{i j}^{k}+C_{S W I T} \sum_{i j \in \Omega_{S W I T n e w}} n x_{i j} \cdot\left[o c_{i j}^{k}-o c_{i j}^{0}\right]^{2} \cdot x_{i j}^{k}\right\} \\
& C_{i n t e r}(t)=k_{t}^{N P V} \cdot T \cdot \sum_{k \in \Omega_{k}} \operatorname{Pr}_{k} \cdot \sum_{i \in \Omega_{b}} V O L L_{i} \cdot L f_{i}(T) \cdot \\
& P L C_{i}^{k}
\end{aligned}
$$

Substation O\&M costs (2) are the sum of discounted $£ / M V A h$ and $£ / M V A / 8760$ costs multiplied by the time period length, $T$, and substation rating, $S_{s}^{\max }$, for each considered regime $k$. Binary variable $m_{s}^{k}$ determines whether a substation $s$ supplies the network or not. Operating regimes $k$ denote intact network and contingencies studied to give compliance with the national planning standards; their mathematical models are called security constraints. Line maintenance costs (3) consist of three essentially different terms. The first is circuit maintenance costs expressed via specific costs $C M S_{\text {line }}$ in $£ / y r / \mathrm{km}$, whilst the second is the cost of circuit repair in case of a contingent regime $k$ (i.e. when $x_{i j}^{k}=0$ ). The remaining terms define maintenance costs of different types of 
switchgear during period $T$; it was assumed that the exact location of new switchgear can be varied in the area close to the 'optimal' QoS locations. Cost of variable electricity losses (4) is specified for period $T$ and operating regimes $k$ using the line loss factors $\operatorname{Llf}(T)$ for all closed in-service branches $i j$.

Discounted switching costs (5) consist of three terms; the first describes switching costs of the existing switchgear, whilst the second and third terms represent switching costs of new CB-reclosers and switches. Finally, interruption costs (6) are computed using load curtailments at each node $P L C_{i}^{k}$, load factors $L f_{i}(T)$ and the value of the lost load $V O L L_{i}$.

Constraints of the optimization model are classified into two groups: a) Power flow; and b) Logical. Power flow constraints are given by relations (7)-(11):

$m_{f S}^{k} \cdot P_{G i}^{k}+P_{D G i}^{k}-P_{D i}^{k}+P L C_{i}^{k}-\sum_{i j \in \Omega_{l}} o c_{i j}^{k} \cdot x_{i j}^{k} \cdot P_{i j}^{k}(\cdot)=$

$0 \quad\left\{\forall i \in \Omega_{b}\right\} \quad\left\{\forall k \in \Omega_{k}\right\}$

$m_{f S}^{k} \cdot Q_{G i}^{k}+Q_{D G i}^{k}-Q_{D i}^{k}+P L C_{i}^{k} \cdot\left(\frac{Q_{D i}^{k}}{P_{D i}^{k}}\right)-\sum_{i j \in \Omega_{l}} o c_{i j}^{k} \cdot x_{i j}^{k}$.

$Q_{i j}^{k}(\cdot)=0 \quad\left\{\forall i \in \Omega_{b}\right\} \quad\left\{\forall k \in \Omega_{k}\right\}$

$o c_{i j}^{k} \cdot x_{i j}^{k} \cdot I_{i j}^{k}(\cdot)^{2} \leq\left(\bar{I}_{i j}^{k}\right)^{2} \quad\left\{\forall i j \in \Omega_{l}\right\}$

$\left(n x_{i j}+n y_{i j}\right) \cdot o c_{i j}^{k} \cdot x_{i j}^{k} \cdot I_{i j}^{k}(\cdot)^{2} \leq\left(n y_{i j} \cdot\left(\bar{I}_{i j}\right)^{C B / R e c}+\right.$

$\left.n x_{i j} \cdot\left(\bar{I}_{i j}\right)^{S W}\right)^{2} \quad\left\{\forall i j \in \Omega_{C B / \text { RECnew }} \cup \Omega_{\text {SWnew }}\right\}$

$\underline{V}^{k} \leq V_{i}^{k} \leq \bar{V}^{k}$

$\left\{\forall i \in \Omega_{b}\right\}$

Nodal active and reactive power equations (7) and (8) are set for all regimes $k$, the power 'injection' into a feeder is controlled by binary variables $m_{f s}^{k}$ and (7) and (8) contain load curtailments $P L C_{i}^{k}$ that are used to find interruption costs (6). Circuit thermal limits and new switchgear thermal constraints are defined by inequalities (9) and (10), whilst inequalities (11) specify nodal voltage limits by regimes $k$. Calculation of branch active power flow $P_{i j}^{k}(\cdot)$, reactive power flow $Q_{i j}^{k}(\cdot)$ and current $I_{i j}^{k}(\cdot)$ is presented in [81]. Regimes $k, k \neq 0$, specify the security constraints that need to be satisfied in accordance with the planning standards [29].

Logical constraints are given by expressions (12)-(22):

$\left(n x_{i j}+n y_{i j}\right) \leq 1 \quad\left\{\forall i j \in \Omega_{C B / R E C n e w} \cup \Omega_{\text {SWnew }}\right\}$

$\left(1-o c_{i j}^{\mathrm{k}}\right) \cdot\left[1-\left(n x_{i j}+n y_{i j}\right)\right]=0 \quad\left\{\forall i j \in \Omega_{C B / R E C n e w} \mathrm{U}\right.$

$\left.\Omega_{\text {SWnew }}\right\}$

$m_{s}^{k}-\sum_{\Omega_{F s}} m_{f s}^{k} \leq 0$

$\left\{\forall s \in \Omega_{S}\right\} \quad\left\{\forall k \in \Omega_{k}^{a b n}\right\}$

$\left(1-m_{s}^{k}\right) \cdot \sum_{\Omega_{F s}} m_{f S}^{k}=0$

$\left\{\forall s \in \Omega_{S}\right\} \quad\left\{\forall k \in \Omega_{k}^{a b n}\right\}$

$\sum_{\Omega_{N O P}} O c_{i j}^{k} \leq N_{N O P}$

$\left\{\forall k \in \Omega_{k}^{a b n}\right\}$

$\sum_{\Omega_{S}} m_{S}^{k} \leq N_{S}$

$\sum_{\Omega_{S}} \sum_{\Omega_{F S}} m_{f S}^{k} \leq N_{F}$

$\left\{\forall k \in \Omega_{k}^{a b n}\right\}$

$\sum_{i j \in \Omega_{l}} o c_{i j}^{k} \cdot x_{i j}^{k} \cdot f_{i j}^{k}=K_{i}$

$\left\{\forall k \in \Omega_{k}^{a b n}\right\}$

$\left|f_{i j}^{k}\right| \leq N_{D G} \cdot o c_{i j}^{k} \cdot x_{i j}^{k}$

$\left\{\forall i \in \Omega_{b}\right\}$

$\sum_{i j \in \Omega_{l}} o c_{i j}^{k}=n_{b}^{k}-1$

$\left\{\forall i j \in \Omega_{l}\right\}$

$\sum_{i j \in \Omega_{l}} o c_{i j}^{k} \cdot x_{i j}^{k}=n_{b}^{k}-\sum_{\Omega_{S}} m_{S}^{k}$

$\left\{\forall k \in \Omega_{k}^{\text {nor }}\right\}$

Constraints (12) show that either a new $\mathrm{CB} /$ recloser or a switch can be installed in branch $i j$, whilst relations (13) link the branch operation status with the existence of new switchgear. Relations (14) and (15) specify relationship between back-feeding substations and associated feeders; when a feeder $f$ is used $\left(m_{f s}^{k}=1\right)$, the substation binary variable $m_{s}^{k}=1$ and vice versa. Company-specific restoration policy is specified via relations (16)-(18). Constraints (16) specify maximum number of normally open switches, whilst expressions (17) and (18) define maximum number of backfeeding substations and feeders used for back-feeding.

Where DG units are connected to the network, the optimization model can generate the solution with isolated island(s). This situation is prevented using the concept of 'fictitious power flows' [81], where fictitious unity load is specified at each DG node providing fictitious power flows over the entire network and thus prohibiting network islanding; this is given by relations (19) and (20). Finally, radial configuration of both intact and contingent regimes is guaranteed by expressions (21) and (22), respectively.

\section{B. Simplified Model}

The main idea is that the optimal switchgear locations found in the QoS planning stage cannot be varied in this stage. The optimization model (2)-(22) is simplified accordingly. The goal is to compare the full and the simplified models and conclude about the accuracy of the new switchgear locations from the QoS stage (see results in the next Section). Note that the simplified model can also be used for the (near) real time network reconfiguration (say, on an hourly basis).

\section{NETWORKS \& RESULTS FOR THE QOS PLANNING STAGE}

Methodologies for the QoS planning are initially tested on the 69-bus network (Fig. 7). The test network includes optimal network investments calculated in the first, investment stage [17] -Table I, whilst network parameters are given in [81-83]. New circuits 27-65 and 62-70 as well as new switchgear 54-55 are constructed, whilst circuits 1-2, 2-3 and 3-4 are reinforced, branch 12-13 is decommissioned and CB 1-2 is upgraded. Other QoS parameters are listed in Table II.

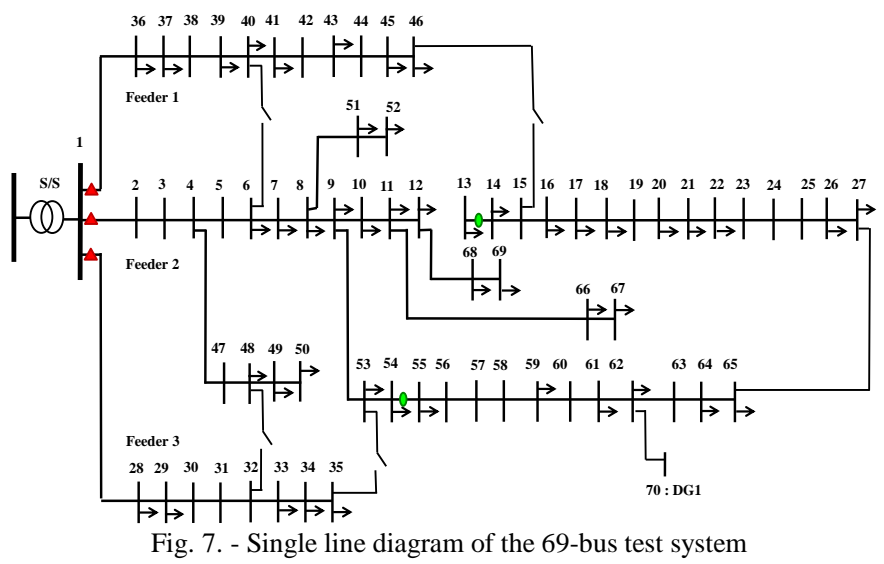

TABLE I - OPTIMAL INVESTMENT SOLUTIONS FOR 69 BUS SySTEM [17]

\begin{tabular}{|c|c|c|c|}
\hline \multicolumn{2}{|c|}{ Planning Period 1 } \\
\hline $\begin{array}{c}\text { Load Level } \\
\text { DG Capacity }\end{array}$ & $\begin{array}{c}\text { Invest. } \\
\text { Costs (£) }\end{array}$ & \multicolumn{2}{|c|}{ Assets Construction and Reinforcements } \\
\hline \multirow{3}{*}{ LL $: 100 \%$} & \multirow{2}{*}{$£ 168,812$} & Branch & $\underline{27-65}, 62-70,1-2,2-3,3-4$ \\
\cline { 3 - 4 } DG $: 100 \%$ & & Switch & $\underline{54-55}, 1-2$ \\
\cline { 3 - 4 } & & Decommission & $12-13$ \\
\hline
\end{tabular}


TABLE II - PARAMETERS IN THE QOS OPTIMIZATION MODELS

\begin{tabular}{|l|l|}
\hline \multicolumn{1}{|c|}{ Parameter } & \multicolumn{1}{c|}{ Value } \\
\hline Failure Rate & $0.065 / \mathrm{km}$-year \\
\hline$C I$ Incentive & $£ 5.84 / 100$ customers \\
\hline$C M L$ Incentive & $£ 17.85 /$ hour/customer \\
\hline \multirow{2}{*}{ Switchgear Construction Cost } & $\begin{array}{l}\text { CB/Recloser: } £ 6,000 \\
\text { Sectionalizing switch: } £ 1,500\end{array}$ \\
\hline \multirow{2}{*}{ Automation/Remote Control Cost } & $\begin{array}{l}\text { CB/Recloser: } £ 5,000 \\
\text { Sectionalizing switch: } £ 2,000\end{array}$ \\
\hline Number of Customers/feeder & 2286 \\
\hline Branch Lengths $(\mathrm{km})$ & $0.45 \mathrm{~km}-2.0 \mathrm{~km}$ \\
\hline \multirow{2}{*}{ Switching Time } & Automation: 1 minute \\
\cline { 2 - 2 } & Manual: 30 minutes \\
\hline Repair Time & 5 hours \\
\hline Switchgear Life & 20 years \\
\hline
\end{tabular}

QoS investment programme is first found utilizing the GA and the results are summarized in Table III. All three switching devices (4-5, 27-65 and 61-62) were installed on Feeder 2 that supplies majority of the customers. New CB 2765 was automated and automation was also proposed for the NO switch 15-46, as well as for the existing switch in branch 54-55.The initial $C I$ and $C M L$ indices were $2.303 \mathrm{f} /$ cust and $6.336 \mathrm{~h} /$ cust, whilst the optimized indices were $1.394 \mathrm{f} /$ cust and $2.446 \mathrm{~h} /$ cust. The final optimal network configuration is defined by the NO switches in branches 6-40, 32-48, 4-5 and 54-55, indicating that several load nodes were transferred from Feeder 2 to the adjacent Feeders 1 and 3. Table IV presents ranked network configurations (GA inner loop - Fig. 3) for the optimal QoS investments shown in Table III. The optimal configuration is in the first row and net benefits are $£ 400$.

The total number of investment interventions in GA studies was limited to 6 new devices and automation of 6 switches, because of the diminishing $C I / C M L$ monetary benefits with the increased investments. The outer, investment loop of Fig. 3 usually converged in $<10,000$ iterations, whilst the inner loop, driven by the number of network loops was solved in $<500$ iterations. All computations were very fast due to the application of the reliability based branch exchange method. TABLE III - QOS INVESTMENTS USING GA APPROACH

\begin{tabular}{|l|l|c|c|}
\hline \multicolumn{2}{|c|}{ Items } & Branch & Costs \\
\hline \multirow{3}{*}{ Automation } & Existing NOP & $15-46$ & $£ 2,000$ \\
\cline { 2 - 4 } & Existing switch & $54-55$ & $£ 2,000$ \\
\cline { 2 - 4 } & New circuit breaker & $27-65$ & $£ 5,000$ \\
\hline \multirow{2}{*}{$\begin{array}{l}\text { New } \\
\text { Construction }\end{array}$} & Circuit breaker & $27-65$ & $£ 6,000$ \\
\cline { 2 - 4 } & Switch & $4-5,61-62$ & $£ 3,000$ \\
\hline \multicolumn{2}{|l|}{ Total QoS Investment } & & $£ 18,000$ \\
\hline Annuity, $A$ & & $£ 1,444$ \\
\hline Yearly Revenue, $R$ & & $£ 1,844$ \\
\hline Yearly Benefits $(R-A)$ & & $£ 400$ \\
\hline
\end{tabular}

TABLE IV - GA CONFIGURATIONS FOR QOS INVESTMENTS FROM TABLE III

\begin{tabular}{|c|c|}
\hline Ranked Network Configurations & Open Points \\
\hline 1 & $6-40,32-48,4-5,54-55$ \\
\hline 2 & $6-40,32-48,4-5,27-65$ \\
\hline 3 & $6-40,32-48,35-53,54-55$ \\
\hline 4 & $6-40,32-48,35-53,27-65$ \\
\hline 5 & $6-40,32-48,4-5,61-62$ \\
\hline 6 & $6-40,32-48,35-53,61-62$ \\
\hline 7 & $4-5,32-48,35-53,15-46$ \\
\hline 8 & $4-5,32-48,35-53,61-62$ \\
\hline 9 & $4-5,32-48,35-53,54-55$ \\
\hline 10 & $4-5,32-48,35-53,27-65$ \\
\hline
\end{tabular}

'Optimal' QoS investments obtained using the rule-based approach of Fig. 6 are shown in Table V; usually 5-8 investment scenarios were studied (loop in Fig. 6). 69-bus network is characterized by poor $C M L$ performance indicating that switchgear automation may give substantial benefits. The main difference between the GA and the rule-based results is the level of automation. Initially NO switches 15-46 and 3553, existing switch 54-55 as well as new breaker 27-65 and new switch 61-62 were automated. New automated breaker was installed at the midpoint of the longest path in the network (branch 27-65), new automated switch in branch 61-62 and a new switch in branch 4-5 so that switching zones are balanced. Note that the new switch 4-5 was not automated because the $C M L$ benefit could not cover the automation cost. Final $C I$ and $C M L$ indices were reduced to $1.394 \mathrm{f} /$ cust and $2.336 \mathrm{~h} /$ cust, respectively, giving the net yearly benefit of $£ 127$. It can be concluded that the rule-based engineering approach produced higher cost - higher benefit solution due to increased level of automation, whilst the total net $£$ benefit was slightly smaller.

Steps to find the best radial network configuration for the QoS investments from Table $\mathrm{V}$ are illustrated in Fig. 8. A disconnected switching zone is added to the already connected zone with the lowest total number of customers, ensuring the differences between switching zones are balanced and preventing network loops. The optimal NOPs are 6-40, 4-5, 32-48 and 54-55 and they are highlighted in yellow in Fig. 8.

TABLE V - QOS INVESTMENT USING RULE-BASED APPROACH

\begin{tabular}{|l|l|c|c|}
\hline \multicolumn{2}{|l|}{ Items } & Branch & Costs \\
\hline \multirow{4}{*}{ Automation } & Existing NOPs & $15-46,35-53$ & $£ 4,000$ \\
\cline { 2 - 4 } & Existing switch & $54-55$ & $£ 2,000$ \\
\cline { 2 - 4 } & New circuit breaker & $27-65$ & $£ 5,000$ \\
\cline { 2 - 4 } & New switch & $61-62$ & $£ 2,000$ \\
\hline \multirow{2}{*}{$\begin{array}{l}\text { New } \\
\text { Construction }\end{array}$} & Circuit breaker & $27-65$ & $£ 6,000$ \\
\cline { 2 - 4 } & Switch & $4-5,61-62$ & $£ 3,000$ \\
\hline \multicolumn{2}{|l|}{ Total QoS Investment } & & $£ 22,000$ \\
\hline Annuity, $A$ & & $£ 1,765$ \\
\hline \multicolumn{2}{|l|}{ Yearly Revenue, $R$} & & $£ 127$ \\
\hline \multicolumn{2}{|l}{ Yearly Benefits $(R-A)$} & & \\
\hline
\end{tabular}

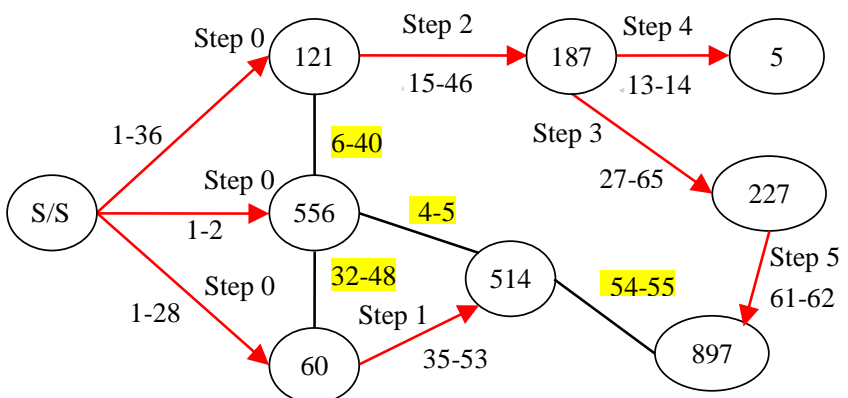

Fig. 8. - Single line diagram of the 69-bus test system via switching zones

To model uncertainties within the QoS stage, it was assumed that additional 400 customers are connected at nodes 38 and 42 (Scenario 1). The results of application of the GA and the rule-based approach are summarized in Table VI. Compared to the original QoS solutions, an additional switch was needed in branch 41-42 on Feeder 1 and the new breaker location was slightly modified to branches 24-25 or 25-26. Comparison of the GA method and the rule-based approach showed higher investments in automation and higher benefits of the rulebased approach, but the GA method produced overall better solution (£506). The optimal radial configuration found by the 
GA approach was to keep switches 4-5, 6-40, 32-48, and 5455 open, whilst 'greedy search' showed that switches 4-5, 6$40,32-48$, an 61-62 need to be opened. Note that the yearly benefits in $f / y r$ are relatively small in all cases presented in Tables V and VI because discounting was done over 20 years (switchgear lifetime) and the primary goal was to cover all QoS investments by the revenue from the regulatory QoS incentive regime (i.e. all QoS investments are not funded from another investment pot).

\begin{tabular}{|c|c|c|c|c|c|}
\hline \multirow{2}{*}{\multicolumn{2}{|c|}{ QoS Investment }} & \multicolumn{2}{|c|}{ GA Approach } & \multicolumn{2}{|c|}{$\begin{array}{l}\text { Rule-Based } \\
\text { Approach }\end{array}$} \\
\hline & & Branch & Costs & Branch & Costs \\
\hline \multirow{4}{*}{ Automation } & $\begin{array}{l}\text { Existing } \\
\text { NOP }\end{array}$ & $15-46$ & $£ 2,000$ & $15-46$ & $£ 2,000$ \\
\hline & $\begin{array}{l}\text { Existing } \\
\text { switch }\end{array}$ & $54-55$ & $£ 2,000$ & $54-55$ & $£ 2,000$ \\
\hline & New CB & $24-25$ & $£ 5,000$ & $25-26$ & $£ 5,000$ \\
\hline & New switch & & & $\begin{array}{l}61-62 \\
41-42\end{array}$ & $£ 4,000$ \\
\hline \multirow{2}{*}{$\begin{array}{l}\text { New } \\
\text { Construction }\end{array}$} & $\begin{array}{l}\text { Circuit } \\
\text { breaker }\end{array}$ & $24-25$ & $£ 6,000$ & $25-26$ & $£ 6,000$ \\
\hline & Switch & $\begin{array}{c}4-5 \\
61-62 \\
41-42 \\
\end{array}$ & $£ 4,500$ & $\begin{array}{c}4-5 \\
61-62 \\
41-42 \\
\end{array}$ & $£ 4,500$ \\
\hline \multicolumn{2}{|c|}{ Total QoS Investment } & & $£ 19,500$ & & $£ 23,500$ \\
\hline \multicolumn{2}{|l|}{ Annuity, $A$} & & $£ 1,565$ & & $£ 1,886$ \\
\hline \multicolumn{2}{|c|}{ Yearly Revenue, $R$} & & $£ 2,071$ & & $£ 2,165$ \\
\hline \multicolumn{2}{|c|}{ Yearly Benefits $(R-A)$} & & $£ 506$ & & $£ 279$ \\
\hline
\end{tabular}

Additional QoS studies were done to find: a) Impact of the number of feeders considered simultaneously; and b) Impact of the constrained budget. The 69-bus network was extended by adding the fourth feeder that has 26 load points, supplies 516 customers and is connected to the original network via a NO switch 58-89 (Fig. 9). Following study cases were done:

Study Case 1 - QoS planning of the whole extended network with no budget constraints.

Study Case 2 - QoS planning of the whole network with budget constraint of $£ 22,000$.

Study Case 3 - Separate QoS planning of the original network and the added Feeder 4 with no budget constraints.

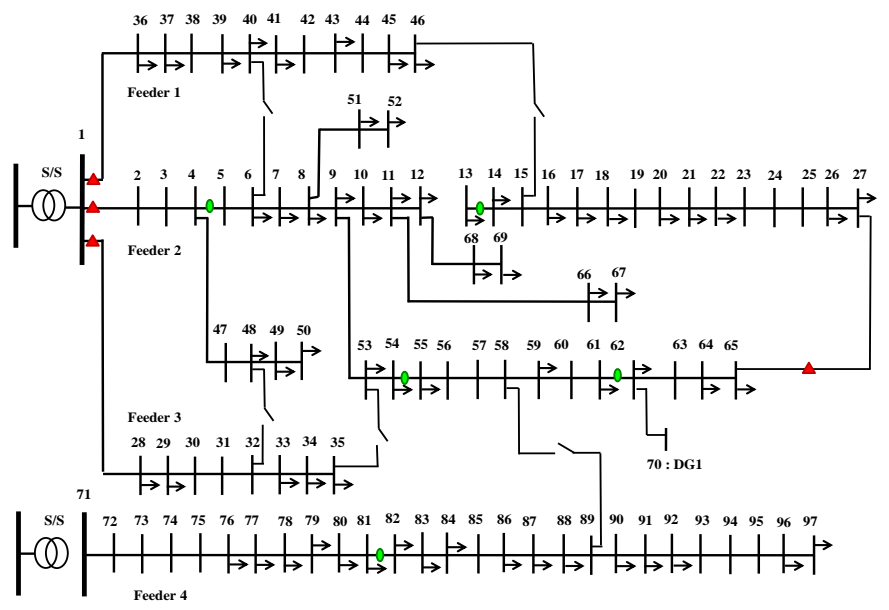

Fig. 9. - 69-bus test network extended with an adjacent feeder

A comparison of the results of three study cases is shown in Table VII. In Case 1, QoS investments comprised original optimal solutions from Table $\mathrm{V}$, as well as installation of a new automated switch 81-82 on Feeder 4 and automation of the NO switch 58-89; the higher total capital QoS investments resulted in higher reliability improvement. In Case 2, the budget covered the original optimal QoS investments from Table $\mathrm{V}$ and there was no room for further investing. The optimal network configuration showed transfer of load points between switches 54-55 and 61-62 on Feeder 2 to the new Feeder 4 indicating importance of studying the entire network. Finally, in Case 3, optimal QoS investments on the original network were the same as those presented in Table V and they amounted to $£ 22,000$ without budget constraints. An additional switch was installed on Feeder 4 (hence no improvement in CIs but improvement in CMLs on circuit $b$. as shown in Table VII), but the corresponding monetary

\begin{tabular}{|c|c|c|c|}
\hline & Study 1 & Study 2 & Study $3 *$ \\
\hline$\Delta C I f / c u s t$ & 0.928 & 0.928 & $\begin{array}{l}\text { a. } 0.9084 \\
\text { b. } 0.000\end{array}$ \\
\hline$\triangle C M L h / c u s t$ & 4.131 & 3.672 & $\begin{array}{l}\text { a. } 4.000 \\
\text { b. } 0.469\end{array}$ \\
\hline Total QoS Investment & $£ 27,500$ & $£ 22,000$ & $\begin{array}{c}\text { a. } £ 22,000 \\
\text { b. } £ 1,500\end{array}$ \\
\hline Annuity, $A$ & $£ 2,207$ & $£ 1,765$ & $\begin{array}{c}\text { a. } £ 1,765 \\
\text { b. } £ 120\end{array}$ \\
\hline Yearly Revenue, $R$ & $£ 2,361$ & $£ 2,006$ & $\begin{array}{c}\text { a. } £ 1,892 \\
\text { b. } £ 43\end{array}$ \\
\hline Yearly Benefits $(R-A)$ & $£ 154$ & $£ 241$ & $\begin{array}{l}\text { a. } £ 127 \\
\text { b. }-£ 77\end{array}$ \\
\hline
\end{tabular}

reliability benefits of Feeder 4 alone were not sufficient to justify the investment on it (net benefit $<0$ for circuit $b$. in Table VII). This highlighted again the advantage of simultaneous QoS planning of several feeders within an area.

\section{RESULTS FOR MINIMIZATION OF OPERATION COSTS}

69-bus test system of Fig. 7 with QoS investments shown in Table $\mathrm{V}$ is used to test the developed models for minimization of operation costs. Winter peak regime on intact network $(k=0)$ is studied in conjunction with three 'critical' outages [17]: first section 1-2 outage $(k=1)$, outage of line 6-7 $(k=2)$ and outage of line 53-54 $(k=3)$. Additional parameters used in operation cost minimization are listed in Table VIII.

\begin{tabular}{|l|l|}
\multicolumn{2}{|c|}{ TABLE VIII- PARAMETERS IN OPERATION OPTIMIZATION MODELS } \\
\hline \multicolumn{1}{|c|}{ Parameter } & \multicolumn{1}{c|}{ Value } \\
\hline Discount Rate & $5 \%$ \\
\hline \multirow{3}{*}{ Yearly Maintenane Costs } & $\begin{array}{l}\text { Substation }: £ 4000 /(\mathrm{MVA} . \mathrm{yr}) \\
\text { Line }: £ 900 /(\mathrm{km} . \mathrm{yr}) \\
\text { Circuit Breaker }: £ 160 / \mathrm{yr} \\
\text { Switches }: £ 30 / \mathrm{yr}\end{array}$ \\
\hline Operation Costs & $\begin{array}{l}\text { Substation }: £ 1000 /(\mathrm{MVA} . \mathrm{yr}) \\
\text { Switching: } £ 100 / \mathrm{One} \text { Op }\end{array}$ \\
\hline Line repair Cost & $£ 1000$ \\
\hline Substation Rating & $18 \mathrm{MVA}$ \\
\hline Load Factor & 0.75 \\
\hline Energy Loss Cost & $£ 0.25 / \mathrm{kWh}$ \\
\hline VOLL & $£ 17 / \mathrm{kWh}$ \\
\hline
\end{tabular}

Optimization model (2)-(22) and the simplified model are implemented in AIMMS [84]. Optimal yearly costs for the full model (2)-(22) are presented in Table IX for the base case and Scenario 1 (400 added customers). The major contribution 
came from losses and interruptions. Although the load curtailments were quite modest because the operation model is solved after the investment stage, the interruption costs were relatively high due to high $V O L L$ of $£ 17 / \mathrm{kWh}[50]$.

TABLE IX - SUMMARY OF OPERATION COSTS FOR FULL MODEL

\begin{tabular}{|l|c|c|}
\hline \multicolumn{1}{|c|}{ Parameter/ Costs $(\mathfrak{£})$} & Base Case & Scenario 1 \\
\hline Substation O\&M Cost & 89976 & 89976 \\
\hline Assets Maintenance Cost & 45649 & 45759 \\
\hline Interruption Cost & 99450 & 276760 \\
\hline Losses Cost & 186063 & 248083 \\
\hline Switching Cost & 101 & 401 \\
\hline Total Operation Costs & 421239 & 660979 \\
\hline
\end{tabular}

The $k W$ load curtailments in contingency regimes $k=1,2,3$ are plotted in Fig. 10 for the Base Case, whilst annual nondelivered energies in $k W h$ in all studied regimes $k=0,1,2,3$ are shown in Table $\mathrm{X}$ for the Base Case and Scenario1; note probabilities $P r_{k}$ were used to find non-delivered energies eq. (6). During section 1-2 outage, a total of $400 \mathrm{~kW}$ of load was shed; demand points on Feeder 2 were supplied by closing the NO switches 32 - 48, 35-53 and 15-46 and opening switches 4-5 and 54-55. The amount of total shed load rose to $1000 \mathrm{~kW}$ in Scenario 1, whilst somewhat lower total $\mathrm{kW}$ load sheddings were obtained for other outages $k=2,3$ in both studies. The total $k W h$ losses amounted to $\sim 3 \%$ of the supplied energy and $k W$ losses were higher in contingent regimes. In Scenario 1, costs of interruptions, losses and switching were higher as bigger loads had to be supplied on Feeder 1. Higher current flows also required additional switching.

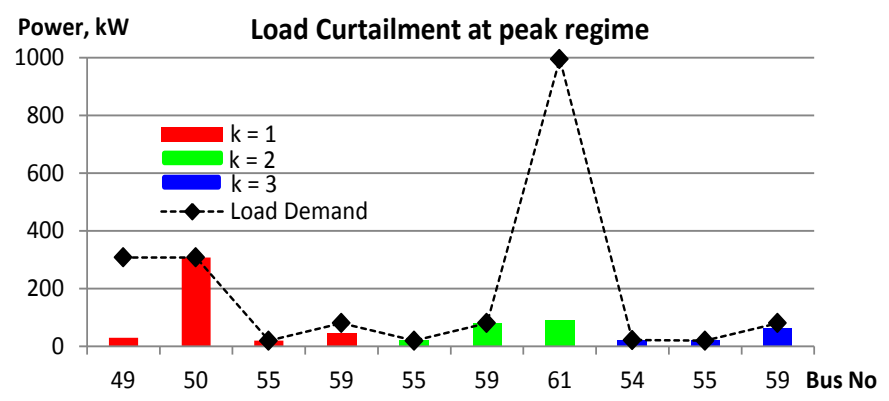

Fig. 10 - Active load curtailments in studied outage regimes

TABLE X - CURTAILED LOADS AND ENERGY LOSSES IN STUDIED REGIMES

\begin{tabular}{|c|c|c|c|c|c|}
\hline \multirow{2}{*}{$\begin{array}{c}\text { Regi } \\
\text { me, } \boldsymbol{k}\end{array}$} & \multirow{P_{\boldsymbol{~}}}{*}{} & $\begin{array}{c}\text { Bnergy } \\
\text { Curtailed } \\
(\mathbf{k W h})\end{array}$ & $\begin{array}{c}\text { Energy } \\
\text { Losses } \\
(\mathbf{k W h})\end{array}$ & $\begin{array}{c}\text { Energy } \\
\text { Curtailed } \\
(\mathbf{k W h})\end{array}$ & $\begin{array}{c}\text { Energy } \\
\text { Losses } \\
(\mathbf{k W h})\end{array}$ \\
\hline 0 & 0.9965 & 0 & 649905 & 0 & 879110 \\
\hline 1 & 0.0015 & 3943 & 42287 & 9855 & 58788 \\
\hline 2 & 0.0010 & 1237 & 26036 & 1997 & 28435 \\
\hline 3 & 0.0010 & 670 & 26022 & 4428 & 26000 \\
\hline Total & $\mathbf{1 . 0}$ & $\mathbf{5 8 5 0}$ & $\mathbf{7 4 4} 250$ & $\mathbf{1 6 ~ 2 8 0}$ & $\mathbf{9 9 2 ~ 3 3 3}$ \\
\hline
\end{tabular}

Table XI presents comparison of the optimal network configurations in each considered regime $k=0,1,2,3$ for the Base Case. QoS planning stage and operation cost minimization produced slightly different optimal solutions for the new switchgear location. More specifically, QoS location of breaker in branch 27-65 was moved to nearby branch 24-25 in the full operations model.
TABLE XI- OPTIMAL NETWORK CONFIGURATIONS FROM THE FULL MODEL

\begin{tabular}{|l|l|c|}
\hline \multicolumn{2}{|c|}{ Parameter } & Location \\
\hline \multirow{2}{*}{ QoS Stage NOPs } & $4-5,6-40,32-48,54-55$ \\
\hline \multirow{3}{*}{$\begin{array}{l}\text { Open } \\
\text { Switches }\end{array}$} & $\mathrm{K}=0$ & $4-5,6-40,32-48,54-55$ \\
\cline { 2 - 3 } & $\mathrm{K}=1$ & $1-2(\mathrm{O}), 4-5,6-40,54-55$ \\
\cline { 2 - 3 } & $\mathrm{K}=2$ & $1-36,6-7(\mathrm{O}), 32-48,54-55$ \\
\cline { 2 - 3 } & $\mathrm{K}=3$ & $1-28,4-5,32-48,53-54(\mathrm{O})$ \\
\hline
\end{tabular}

A summary of results obtained by the simplified model (Section IV-B) is shown in Table XII for the Base Case. Total operation costs have increased by $£ 10,386(\sim 2.5 \%)$ compared to the full model solutions (Table IX), as new CB location was changed. Higher load curtailments were seen in contingent regimes $k=2,3$ when compared to the full model solutions.

TABLE XII - SUMMARY OF OPERATION COSTS FOR SIMPLIFIED MODEL

\begin{tabular}{|l|c|}
\hline \multicolumn{1}{|c|}{ Parameter } & Costs $(\mathfrak{(})$ \\
\hline Substation O\&M Cost & 89976 \\
\hline Assets Maintenance Cost & 45649 \\
\hline Interruption Cost & 113129 \\
\hline Losses Cost & 182769 \\
\hline Switching Cost & 102 \\
\hline Total Operation Costs & 431625 \\
\hline
\end{tabular}

\section{COMPARATIVE STUDIES}

It was not possible to compare the proposed methodology directly with any so-far developed approach because all of them model reliability aspects through the customer outage costs and not through the regulatory QoS incentive rates on $C I$ and $C M L$ indices (section I). Approach [22] was deemed "appropriate" and it was selected for comparison; it determines optimal locations of new switchgear by minimizing the switchgear capital costs and costs of nonsupplied energy while meeting branch thermal capacity limits, and a limit on SAIDI. The comparison was done in the following way:

- Utility-based approach: optimal switchgear locations and CI/CML benefits are determined within the QoS stage, whilst operational cost minimization model (2)-(22) was used to find the optimal cost of non-supplied energy.

- Approach [22]: operational cost model (2)-(22) was modified to mimic the approach [22] (objective function component (3) was modified to account for switchgear capital costs, one operating regime $k$ was studied, etc.); the optimal switchgear locations from the method [22] were used to calculate changes in the network CIs and $C M L s$ and corresponding $£$ benefits (first term in (1)).

The base network in Fig. 7 and all the relevant parameters in Table II were used for the study. A summary of results is shown in Table XIII.

TABLE XIII - COMPARISON OF THE PROPOSED MODEL WITH METHOD [22]
\begin{tabular}{|l|c|c|}
\hline \multicolumn{1}{|c|}{ Parameter } & Proposed Method & Method [22] \\
\hline $\begin{array}{l}\text { Costs of non- } \\
\text { supplied energy }\end{array}$ & $£ 75471$ & $£ 72175$ \\
\hline New switchgears & $\begin{array}{l}\text { Breaker: 27-65 } \\
\text { Switch : 4-5, 61-62 }\end{array}$ & $\begin{array}{l}\text { Breaker: 24-25,39-40 } \\
\text { Switch : 5-6, 61-62 }\end{array}$ \\
\hline$\Delta C$ I f/cust & 0.908 & 1.114 \\
\hline$\Delta C M L h /$ cust & 3.89 & 3.991 \\
\hline Annuity, $A$ & $£ 1,444$ & $£ 2,327$ \\
\hline Yearly Revenue, $R$ & $£ 1,844$ & $£ 1,918$ \\
\hline $\begin{array}{l}\text { Yearly Net Benefits } \\
(R-A)\end{array}$ & $£ 400$ & $-£ 409$ \\
\hline
\end{tabular}


The costs of non-supplied energy obtained using the utilitybased approach with single objective function (6) amounted to $£ 75,471$, which is a significant reduction of $\sim 24 \%$ from the costs obtained with the full operation model utilizing composite objective function (2)-(6) (Table IX). Method [22] gave better results in terms of the reduced costs of nonsupplied energy of $£ 72,175$, as one additional breaker/recloser was allocated to branch 39-40. Optimal locations of other new switching devices 5-6, 24-25, and 61-62 lied in a 'close' proximity of the optimal locations found in the QoS stage of the utility-based approach. The switchgear locations found with the method [22] were then used to calculate changes in the network $C I s$ and $C M L s$ and corresponding monetary benefits. It can be observed that installation of an automated breaker/recloser on branch 39-40 (method [22]) resulted in higher improvement of $C I s$ and $C M L s$, as well as in increased CI/ CML yearly revenue of $£ 1,918 / \mathrm{yr}$ when compared to the revenue of $£ 1,844 / \mathrm{yr}$ determined by the proposed approach. Likewise, the annual capital costs increased from $£ 1,444 / \mathrm{yr}$ to $£ 2,327 / \mathrm{yr}$ for method [22], which resulted in negative yearly net benefits of $-£ 409$. These results have proven advantage of the proposed approach in which the QoS stage is based on modelling the QoS incentive regime and not on the customer outage costs. In conclusion, distribution network planning has to look into the problem from a utility's perspective and to consider all regulatory aspects that are in place; to this end, any reliability modelling based on expected energy not served and corresponding customer outage costs is only a proxy.

\section{MODEL SCALABILITY}

The developed methodology was tested on IEEE 69 bus and IEEE 119 bus test systems; this raises the question of model applicability on real-life MV networks, particularly those in rural areas, which can contain several hundreds of nodes. Two methodological aspects should be looked at:

- Number of the tree nodes in the decision trees, and

- Computational complexity of the developed models.

With regards to the first aspect, the objective is to reduce the number of tree nodes. This can be achieved by either reducing the number of planning intervals in the decision tree, or by reducing the number of scenarios, or both. QoS studies are done on an irregular basis, which implies at least once in the regulation period (typically 5 years). However, network operational cost minimization studies are done on a regular basis (say, twice a year), so that the planning interval $\Delta t$ (Fig. 2) can only be increased if it is assumed that the operating conditions will not change significantly over "a couple of years"; this is driven, above all, by applications for new connections and strategic development plans. On the other hand, number of scenarios in a planning period is reduced by neglecting tree nodes with low probabilities.

Performance of the QoS GA - based model is driven by three factors: a) Number of potential investments; b) Number of network loops; and c) Method for reliability calculation. In case of large rural/mixed networks, number of potential locations for new switchgear is limited by feeder structure, available physical locations, customer numbers etc. The number of existing switchgear is typically small, which shows that both the number of automation alternatives and network loops is significantly limited. Given that the reliability calculation [75] is very fast with no convergence problems, the scalability of the QoS GA based method is quite good. Similar analysis and justifications can be applied to the QoS engineering - based method, which is being used in utilities. This problem can be solved even faster using the long-term company experience.

Operational cost minimization problem (2)-(22) is a MINLP model, where the following factors affect the model solution: a) Complexity of physical and logical constraints; and b) Problem size. The full model (2)-(22) is highly complex and it is recommended to use the simplified model (section IV.B) in real-life. A powerful workstation is needed to solve large networks; however, there is still a possibility that the simplified model will not converge. In that respect, development of a linearized MILP model is the only solution that guarantees the model convergence.

\section{CONCLUSION}

The paper presents operational planning stage of the integrated planning of medium voltage distribution networks based on utility concepts. This stage is executed after the investment stage and it is divided into two sub-stages, QoS planning and minimization of operational costs. The QoS planning is solved using GA optimization and the approach based on engineering rules, whilst operational cost minimization is set as a mixed-integer nonlinear problem.

The QoS studies have shown that the optimum is pretty much 'flat', that is, differences in optimal values of the net QoS benefits are not big for different investment plans. It is therefore deemed that GA optimization is more appropriate for regulatory regimes without the QoS incentive, because the total investment costs are smaller. In the opposite case, the rule based approach is deemed more suitable, because higher QoS investments provide almost same net benefits and better operational capabilities. The financial benefits of studying several feeders simultaneously have also been demonstrated.

Minimization of the operational costs has indicated that 'optimal' locations of new switchgear from the QoS stage did not change significantly in this sub-stage and therefore the simplified model gives 'good' results when compared to the full model. Besides, the NO points were the same as in the QoS sub-stage (intact network), indicating optimal network configuration can also be found in the reliability optimization where the cost of non-delivered $\mathrm{kWh}$ is high.

The final conclusion is that any reliability modelling shall be done from the utility's perspective by modelling the regulatory QoS incentive regime; any method based on customer outage costs is only a proxy to the former approach.

\section{REFERENCES}

[1] S. K. Khator and L. C. Leung, "Power distribution planning: a review of models and issues," IEEE Trans. on Power Systems, vol. 12, no. 3, pp. 1151-1159, 1997.

[2] P. S. Georgilakis and N. D. Hatziargyriou, "A review of power distribution planning in the modern power systems era: Models, methods \& future research,” Elec Pow Syst Res, vol. 121, pp. 89-100, Apr. 2015.

[3] P. Georgilakis and N. Hatziargyriou, "Optimal Distributed Generation Placement in Power Distribution Networks: Models, Methods \& Future Research," IEEE Trans. on Power Systems, vol. 28, no. 3, pp. 34203428,2013

[4] A. Keane, L.F. Ochoa, C.L.T. Borges, G.W. Ault, A.D. AlarconRodrigez, R.A.F.Currie, F.Pilo, C. Dent, G.P. Harrison, "State-of-the-art 
techniques and challenges ahead for distributed generation planning and optimization", IEEE T on Pow Syst, vol. 28, no. 2, pp. 1493-1502, 2013.

[5] A. Tabares, J. F. Franco, M. Lavorato, and M. J. Rider, "Multistage long-term expansion planning of electrical distribution systems considering multiple alternatives," IEEE Trans. on Power Systems, vol. 31, no. 3, pp. 1900-1914, 2016.

[6] R. H. Fletcher and K. Strunz, "Optimal distribution system horizon planning - Part I: Formulation," IEEE Trans. on Power Systems, vol. 22, no. 2, pp. 791-799, 2007.

[7] R. H. Fletcher and K. Strunz, "Optimal distribution system horizon planning - Part II : Application," IEEE Trans. on Power Systems, vol. 22, no. 2, pp. 862-870, 2007.

[8] G. Munoz-Delgado, J. Contreras, and J. M. Arroyo, "Joint expansion planning of distributed generation and distribution networks," IEEE Trans. on Power Systems, vol. 30, no. 5, pp. 2579-2590, 2015.

[9] M. E. Samper and A. Vargas, "Investment decisions in distribution networks under uncertainty with distributed generation - Part I : Model formulation," IEEE T on Pow Syst, vol. 28, no. 3, pp. 2331-2340, 2013.

[10] M. E. Samper and A. Vargas, "Investment decisions in distribution networks under uncertainty with distributed deneration - Part II: Implementation and Results," IEEE Trans. on Power Systems, vol. 28, no. 3, pp. 2341-2351, 2013.

[11] N. C. Koutsoukis, P. S. Georgilakis, and N. D. Hatziargyriou, "Multistage Coordinated Planning of Active Distribution Networks," IEEE Trans. on Power Systems, vol. 8950, no. c, pp. 1-1, 2017.

[12] I. Ziari, G. Ledwich, A. Ghosh, and G. Platt, "Optimal distribution network reinforcement considering load growth, line loss, and reliability," IEEE T on Power System, vol. 28, no. 2, pp. 587-597, 2013.

[13] B. Zeng, J. Zhang, X. Yang, J. Wang, J. Dong, and Y. Zhang, "Integrated planning for transition to low-carbon distribution system with renewable energy," IEEE Trans. on Power Systems, vol. 29, no. 3, pp. 1153-1165, 2014.

[14] A. Cossi, L. da Silva, R. Lázaro, and J. Mantovani, "Primary power distribution systems planning taking into account reliability, operation and expansion costs," IET Generation Transmission and Distribution, vol. 6 , no. 3 , p. $274,2012$.

[15] J. Mantovani, A. Cossi, J. Contreras, and B. Pereira Junior, "Multiobjective multistage distribution system planning using tabu search," IET Generation Transmission and Distribution, vol. 8, no. 1, pp. 35-45, 2014.

[16] S. Haffner, L. Pereira, L. Pereira, L. Barreto, "Multistage model for distribution expansion planning with distributed generation - Part I: Problem formulation," IEEE Trans. on Power Delivery, vol. 23, pp. 915-923, 2008.

[17] N. N. Mansor and V. Levi, "Integrated Planning of Distribution Networks Considering Utility Planning Concepts," IEEE Trans. on Power Systems, vol. 32, no. 6, pp. 4656-4672, 2017.

[18] I. J. Ramirez-Rosado and J. L. Bernal-Agustin, "Reliability and costs optimization for distribution networks expansion using an evolutionary algorithm," IEEE T on Power System, vol. 16, no. 1, pp. 111-118, 2001.

[19] I. J. Ramírez-Rosado and J. A. Domínguez-Navarro, "New multiobjective tabu search algorithm for fuzzy optimal planning of power distribution systems," IEEE Trans. on Power Systems, vol. 21, no. 1, pp. 224-233, 2006.

[20] N. G. Paterakis, A. Mazza, S. F. Santos, O. Erdinc, G. Chicco, A. G. Bakirtzis, and J. P. S. Catalao, "Multi-objective reconfiguration of radial distribution systems using reliability indices," IEEE Trans. on Power Systems, vol. 31, no. 2, pp. 1048-1062, 2016.

[21] J. R. Bezerra, G. C. Barroso, R. Leão, and R. F. Sampaio, "Multiobjective optimization algorithm for switch placement in radial power distribution networks," IEEE Trans. on Power Delivery, vol. 30, no. 2, pp. 545-552, 2015.

[22] L. S. De Assis, J. F. Vizca, F. L. Usberti, C. Lyra, C. Cavellucci, and F. J. Von Zuben, "Switch allocation problems in power distribution systems," IEEE Trans. on Power Systems, vol. 30, no. 1, p. 8, 2015.

[23] G. Muñoz-Delgado, J. Contreras, J.M. Arroyo, "Distribution Network Expansion Planning With an Explicit Formulation for Reliability Assessment", IEEE Trans. on Power Systems, vol. 33, no. 3, pp. 25832596, 2018.

[24] S.Heidari, M. Fotuhi-Firuzabad, S. Kazemi, "Power distribution network expansion planning considering network automation", IEEE Trans. on Power Systems, vol. 30, no. 3, pp.1261-1270, 2015.

[25] G. Muñoz-Delgado, J. Contreras, J.M. Arroyo, "Multistage Generation and Network Expansion Planning in Distribution Systems Considering
Uncertainty and Reliability", IEEE Trans. on Power Systems, vol. 31, no. 5, pp. 3715 - 3728, 2016.

[26] J. Choi, T. Tran, A.A. El-Keib, R. Thomas, H.S. Oh, R. Billinton, “A method for transmission system expansion planning considering probabilistic reliability criteria", IEEE Trans. on Power Systems, vol. 20, no. 3, pp. 1606-1615, 2005.

[27] X. Zhang, L. Che, M. Shahidehpour, A.S. Alabdulwahab, A. Abusorrah, "Reliability-Based Optimal Planning of Electricity and Natural Gas Interconnections for Multiple Energy Hubs", IEEE Trans. on Smart Grid, vol. 8, no. 4, pp. 1658-1667, 2017.

[28] R. Lotero and J. Contreras, "Distribution system planning with reliability," IEEE Trans. on Power Delivery, vol. 26, no. 4, pp. 25522562, 2011.

[29] "Engineering Recommendation P2/6 - Security of Supply", Energy Networks Association, London, UK, July 2006.

[30] A. Pombo, J. Murta-Pina, and V. Pires, "A multiobjective placement of switching devices in distribution networks incorporating distributed energy resources," Electr. Power Syst. Res., vol. 130, pp. 34-45, 2016.

[31] D. Bernardon, M. Sperandio, V. Garcia, L. Canha, A. Abaide, and E. Daza, "AHP decision-making algorithm to allocate remotely controlled switches in distribution networks," IEEE Trans. Power Deliv., vol. 26, no. 3, pp. 1884-1892, Jul. 2011.

[32] E. Carrano, L. Soares, R. Takahashi, R. Saldanha, and O. Neto, "Electric distribution network multiobjective design using a problem-specific Genetic Algorithm," IEEE Trans. Power Deliv., vol. 21, no. 2, pp. 9951005, 2006.

[33] J.C. Lopez, J.F. Franco, and M.J. Rider, "Optimization-based switch allocation to improve energy losses and service restoration in radial electrical distribution systems", IET Generation, Transmission and Distribution, vol. 10, no. 11, pp. 2792-2801, 2016.

[34] A. Abiri-Jahromi and M. Fotuhi-Firuzabad, "Optimized sectionalizing switch placement strategy in distribution systems", IEEE Trans. Power Deliv., vol. 27, no. 1, pp. 362-370, 2012.

[35] R. Billinton and S. Jonnavithula, "Optimal switching device placement in radial distribution systems", IEEE Trans. Power Deliv., vol. 11, no. 3, pp. 1646-1651, 1996.

[36] A. Heidari, V. Agelidis, and M. Kia, "Considerations of sectionalizing switches in distribution networks with distributed generation," IEEE Trans. Power Deliv., vol. 30, no. 3, pp. 1401-1409, Jun. 2015.

[37] A. Heidari, V.G. Agelidis, M. Kia, J. Pou, J. Aghaei, M. Shafie-Khah, J.P.S. Catalão, "Reliability optimization of automated distribution networks with probability customer interruption cost model in the presence of DG units", IEEE Trans. on Smart Grids, vol. 8, no. 1, pp. 305-315, 2017

[38] J. Teng and Y. Liu, "A novel ACS-based optimum switch relocation method," IEEE Trans. Power Syst., vol. 18, no. 1, pp. 113-120, 2003.

[39] A. Moradi and M. Fotuhi-Firuzabad, "Optimal switch placement in distribution systems using trinary particle swarm optimization algorithm," IEEE Trans. Power Deliv., vol. 23, no. 1, pp. 271-279, 2008.

[40] H. Falaghi, M.R. Haghifam, and C. Singh, "Ant Colony optimizationbased method for placement of sectionalizing switches in distribution networks using a Fuzzy multiobjective approach," IEEE Trans. Power Deliv., vol. 24, no. 1, pp. 268-276, Jan. 2009.

[41] C. Chen, C. Lin, H. Chuang, C. Li, M. Huang, and C. Huang, "Optimal placement of line switches for distribution automation systems using Immune Algorithm," IEEE Trans. Power Syst., vol. 21, no. 3, pp. 12091217, 2006

[42] M. Izadi, A. Safdarian, "Financial risk constrained remote controlled switch deployment in distribution networks", IET Generation, Transmission \& Distribution, vol. 12, issue 7, pp. 1547-1553, 2018.

[43] M. Farajollahi, M. Fotuhi-Firuzabad, and A. Safdarian, "Simultaneous Placement of Fault Indicator and Sectionalizing Switch in Distribution Networks", IEEE Trans. on Smart Grids, DOI 10.1109/TSG.2018.2794994, 2018.

[44] M. H. Kapourchali, M. Sepehry, V. Aravinthan, "Fault detector and switch placement in cyber-enabled power distribution network", IEEE Trans. on Smart Grid, vol. 9, issue 2, pp. 980-992, 2018.

[45] M. Lwin, J. Guo, N. Dimitrov, S. Santoso, "Protective device and switch allocation for reliability optimization with distributed generators", IEEE Trans. on Sustainable Energy, DOI 10.1109/TSTE.2018.2850805, 2018.

[46] Ž. Popović, S. Knezević, B. Brbaklić, "Optimal reliability improvement strategy in radial distribution networks with island operation of distributed generation", IET Generation, Transmission \& Distribution, vol. 12, issue: 1, pp. 78-87, 2018. 
[47] Y. Mao and K. N. Miu, "Switch placement to improve system reliability for radial distribution systems with distributed generation," IEEE Trans. Power Syst., vol. 18, no. 4, pp. 1346-1352, 2003.

[48] Y. Xu, C.C. Liu, K. Schneider, and D. Ton, "Placement of remotecontrolled switches to enhance distribution system restoration capability," IEEE Trans. Power Syst., vol. 31, no. 2, pp. 1139-1150, Mar. 2016.

[49] J.C. Lopez, M. Lavorato, M.J. Rider, "Optimal reconfiguration of electrical distribution systems considering reliability indices improvement", Electrical Power and Energy Systems, vol. 78, pp. 837$845,2016$.

[50] Ofgem, “Guide to RIIO-ED1 electricity distribution price control”, 2017.

[51] D. Zhang, Z. Fu, L. Zhang, "Joint Optimization for Power Loss Reduction in Distribution Systems", IEEE Trans. on Power Systems, vol. 23, no. 1, pp. 161-169, 2008.

[52] T. Cormen, C. Leiserson, R. Riverst, C. Stein, Introduction to algorithms, The MIT Press, 2001.

[53] M.E. Samper, A. Vargas, "Investment decisions in distribution networks under uncertainty with distributed generation-Part I: Model formulation", IEEE Trans, Power Syst., vol. 28, no. 3, pp. 2331-2340, 2013.

[54] M.E. Samper, A. Vargas, "Investment decisions in distribution networks under uncertainty with distributed generation-Part II: Implementation and results", IEEE T. Power Syst., vol. 28, no. 3, pp. 2341-2351, 2013.

[55] E.C. Carrano, F.G. Guimaraes, R.H.C. Takahashi, O.M. Neto, F. Campelo, "Electric distribution network expansion under load-evolution uncertainty using an immune system inspired algorithm", IEEE Trans, Power Syst., vol. 22, no. 2, pp. 851-861, 2007.

[56] E. Haesen, J. Driesen, and R. Belmans, "Robust planning methodology for integration of stochastic generators in distribution grids", IET Renew. Power Gen., vol. 1, no. 1, pp. 25-32, Mar. 2007.

[57] Z. Liu, F. Wen, and G. Ledwich, "Optimal siting and sizing of distributed generators in distribution systems considering uncertainties", IEEE Trans. Power Del., vol. 26, no. 4, pp. 2541-2551, Oct. 2011.

[58] M.F. Shaaban; Y.M. Atwa; E.F. El-Saadany, "DG allocation for benefit maximization in distribution networks", IEEE Trans. Power Syst., vol. 28, no. 2, pp. 639-649, 2013.

[59] S.F. Santos, D.Z. Fitiwi, A.W. Bizuayehu, M. Shafie-khah, M. Asensio, J. Contreras, C.M.P. Cabrita, J.P.S. Catalao, "Novel multi-stage stochastic DG investment planning with recourse", IEEE Trans. Sustainable Energy., vol.8, no. 1, pp. 164-178, 2017.

[60] A.A. Chowdhury, D.E.Custer, "A value-based probabilistic approach to designing urban distribution systems", Int. J. Electr. Power Energy Syst., vol. 27 , no. 9, pp. 647-655, 2005.

[61] D.T.C. Wang, L.F. Ochoa, G.P. Harrison, "Modified GA and data envelopment analysis for multistage distribution network expansion planning under uncertainty", IEEE Trans. Power Syst., vol. 26, no. 2, pp. 897-904, 2011.

[62] B.B. Souza, E.G. Carrano, O.M. Neto, R.H.C. Takahashi, "Immune system memetic algorithm for power distribution network design with load evolution uncertainty", Electr. Power Syst. Res., vol. 81, no. 2, pp. 527-537, 2011

[63] A.Alarcon-Rodriguez, E. Haesen, G.W.Ault, J.Driesen, and R. Belmans, "Multi-objective planning framework for stochastic and controllable distributed energy resources", IET Renew. Power Gen., vol. 3, no. 2, pp. 227-238, Jun. 2009.

[64] Y.M. Atwa, E.F. El-Saadany, M.M.A. Salama, and R. Seethapathy, "Optimal renewable resources mix for distribution system energy loss minimization", IEEE T. Power Syst., vol. 25, no. 1, pp. 360-370, 2010.

[65] C. Novoa, and T. Jin, "Reliability centered planning for distributed generation considering wind power volatility", Electr. Power Syst. Res., vol. 81, no. 8, pp. 1654-1661, Aug. 2011.

[66] N. Amjady; A. Attarha; S. Dehghan; A.J. Conejo, "Adaptive robust expansion planning for a distribution network with DERs", IEEE Trans. Power Syst., vol. 33, no. 2, pp. 1698-1715, 2018.

[67] P.M.S. Carvalho; L.A.F.M. Ferreira; F.G. Lobo; L.M.F. Barruncho, "Distribution network expansion planning under uncertainty: a hedging algorithm in an evolutionary approach", IEEE Trans. Power Del., vol. 15, no. 1, pp. 412-416, 2000.

[68] A. Zakariazadeh, S. Jadid, and P. Siano, "Stochastic multi-objective operational planning of smart distribution systems considering demand response programs", Electr. Power Syst. Res., vol. 111, pp. 156-168, Aug. 2014.

[69] A. Zare; C.Y. Chung; J. Zhan; S.O. Faried, "A distributionally robust chance-constrained MILP model for multistage distribution system planning with uncertain renewables and loads", IEEE Trans. Power Syst., DOI 10.1109/TPWRS.2018.2792938, 2018.

[70] V.F. Martins, and C.L.T. Borges, "Active distribution network integrated planning incorporating distributed generation and load response uncertainties", IEEE Trans. Power Syst., vol. 26, no. 4, pp. 2164-2172, 2011.

[71] R.S. Al-Abri; E.F. El-Saadany; Y.M. Atwa, "Optimal placement and sizing method to improve the voltage stability margin in a distribution system using distributed generation”, IEEE Trans. Power Syst., vol. 28, no. 1, pp. 326-334, 2013.

[72] B. Zeng; J. Zhang; X. Yang; J. Wang; J. Dong; Y. Zhang, "Integrated planning for transition to low-carbon distribution system with renewable energy generation and demand response", IEEE Trans. Power Syst., vol. 29, no. 3, pp. 1153-1165, 2014.

[73] Y. Gao; X. Hu; W. Yang; H. Liang; P. Li, "Multi-objective bilevel coordinated planning of distributed generation and distribution network frame based on multiscenario technique considering timing characteristics, IEEE Trans. Sust. Energy, vol. 8, no. 4, pp. 1415-1429, 2017.

[74] Y. M. Atwa and E. F. El-Saadany, "Probabilistic approach for optimal allocation of wind-based distributed generation in distribution systems," IET Renew. Power Gener., vol. 5, no. 1, p. 79, 2011.

[75] R.Billinton, R.N.Allan, "Reliability evaluation of power systems", Springer-Verlag US, Boston, 1996.

[76] M.E.Baran, F.F.Wu, "Network reconfiguration in distribution systems for loss reduction and load balancing", IEEE Trans. on Power Delivery, vol. 4, no. 2, pp. 1401-1407, 1989.

[77] J.Y.Fan, L.Zhang, J.D.McDonald, "Distribution network reconfiguration -Single loop optimization", IEEE Trans. on Power Systems, vol. 11, no. 3, pp. 1643-1647, 1996.

[78] V.Farahani, B.Vahidi, H.A. Abyaneh, "Reconfiguration and Capacitor Placement Simultaneously for Energy Loss Reduction Based on an Improved Reconfiguration Method", IEEE Trans. on Power Systems, vol. 27, no. 2, pp. 587-595, 2012.

[79] M.Srinivas, M.Patnaik, "Adaptive probabilities of crossover and mutation in genetic algorithms", IEEE Trans. Syst., Man, Cybern., vol. 24, no. 4, pp. 656-666, 1994.

[80] DIgSILENT, Germany, https://www.digsilent.de/en/powerfactory.html.

[81] M. Lavorato, J. Franco, M. Rider, and R. Romero, "Imposing radiality constraints in distribution system optimization problems," IEEE Trans. on Power Systems, vol. 27, no. 1, pp. 172-180, 2012.

[82] R. S. Rao, S. V. L. Narasimham, M. R. Raju, and A. S. Rao, "Optimal network reconfiguration of large-scale distribution system using harmony search algorithm," IEEE Trans. Power Syst., vol. 26, no. 3, pp. 1080-1088, 2011.

[83] M. M. Aman, G. B. Jasmon, A. H. A. Bakar, and H. Mokhlis, "Optimum network reconfiguration based on maximization of system loadability using continuation power flow theorem," Electr. Power Energy Syst., vol. 54, pp. 123-133, Jan. 2014.

[84] AIMMS 4.13, AIMMS B.V., Haarlem, The Netherlands, 2015; software available at http://www.aimms.com/.

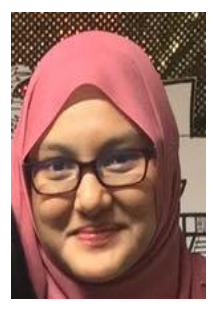

Nurulafiqah Nadzirah Mansor was born in Malaysia in 1987. She received the BEng. degree in electrical engineering from Vanderbilt University, Tennessee, USA in 2008, the MEng degree in power system engineering from University of Malaya, Malaysia in 2013, and the $\mathrm{Ph} . \mathrm{D}$ degree from the University of Manchester, U.K in 2018. From 2008 to 2014, she worked as a process engineer with Texas Instruments (M) Sdn. Bhd. Her research interests include distribution system modelling and analysis, distribution system planning and operation, renewable energy and smart distribution system.

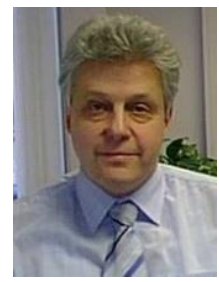

Victor Levi (S'89-M'91-SM'13) received the M.Sc. and $\mathrm{Ph} . \mathrm{D}$. degrees in electrical engineering from the University of Belgrade, Belgrade, Yugoslavia, in 1986 and 1991, respectively. From 1982 to 2001, he was with University of Novi Sad, Novi Sad, Yugoslavia, where he became a Full Professor in 2001. He was with the University of Manchester, Manchester, U.K. from 2001 to 2003, and then with United Utilities and Electricity North West, from 2003 to 2013. In 2013, he rejoined the University of Manchester. 